OPEN ACCESS

Edited by:

Zhong-qiu Liu,

Guangzhou University of Chinese

Medicine, China

Reviewed by:

Lin Han,

The Affiliated Hospital of Qingdao

University, China

Fabio Boylan,

Trinity College Dublin, Ireland

*Correspondence:

Juan Li

Iz198207@126.com

Guangrui Deng

ruiqilin@126.com

Specialty section: This article was submitted to

Ethnopharmacology,

a section of the journal

Frontiers in Pharmacology

Received: 05 March 2021 Accepted: 23 April 2021

Published: 17 May 2021

Citation:

Zhang X, Liu Y, Deng G, Huang B, Kai G, chen K and Li J (2021) A Purified

Biflavonoid Extract From Selaginella moellendorffii Alleviates Gout Arthritis

via NLRP3/ASC/Caspase-1

Axis Suppression.

Front. Pharmacol. 12:676297.

doi: 10.3389/fphar.2021.676297

\section{A Purified Biflavonoid Extract From Selaginella moellendorffii Alleviates Gout Arthritis via NLRP3/ASC/ Caspase-1 Axis Suppression}

\author{
Xueyan Zhang ${ }^{1}$, Yingbo Liu ${ }^{1}$, Guangrui Deng ${ }^{1,2 *}$, Bisheng Huang ${ }^{1}$, Guoyin Kai ${ }^{3}$, Keli chen ${ }^{1}$ \\ and Juan $\mathrm{Li}^{1 *}$ \\ ${ }^{1}$ Key Laboratory of Ministry of Education on Traditional Chinese Medicine Resource and Compound Prescription, Key Laboratory \\ of Resources and Chemistry of Chinese Medicine, College of Pharmacy, Hubei University of Chinese Medicine, Wuhan, China, \\ ${ }^{2}$ Department of Pharmacy, Huanggang Hospital of Traditional Chinese Medicine, Huanggang, China, ${ }^{3}$ College of Pharmacy, \\ Zhejiang Chinese Medical University, Hangzhou, China
}

Background: Activation of nucleotide oligomerization domain-like receptor protein 3 (NLRP3) inflammasome plays a crucial role in gout. Selaginella moellendorffii has been confirmed effective for the treatment of gout in hospital preparations. Flavonoids, such as amentoflavone (AM), are the main active components of this medicine.

Purpose: We aimed to investigate the flavonoid extract (TF) and AM's effects on NLRP3 inflammasome in vitro and their preventive effects on gout in vivo.

Methods: LC-MS method was employed to investigate the chemical profile of TF. The cellular inflammation model was established by lipopolysaccharide (LPS) or monosodium urate (MSU) stimulation. The cell membrane integrality and morphological characteristics were determined by using Lactate dehydrogenase $(\mathrm{LDH})$ assay kits, propidium iodide $(\mathrm{PI})$ stain, and scanning electron microscopy (SEM). The inflammatory cytokines and NLRP3 inflammasome activation were determined using enzyme-linked immunosorbent assay (ELISA), quantitative real-time polymerase chain reaction (RT-PCR), immunofluorescence staining, and western blotting. The acute gout mouse model was induced by MSU injection into footpads, and then the paw edema, inflammatory mediators, and histological examination (HE) were analyzed.

Results: The main constituents in TF are $\mathrm{AM}$ and robustaflavone. In the cellular inflammation model, TF down-regulated the levels of nitric oxide (NO), TNF- $\alpha$, and $\mathrm{LDH}$, suppressed NLRP3 inflammasome-derived interleukin-1 $\beta$ (IL-1 $\beta$ ) secretion, decreased caspase-1 activation, repressed mature IL-1 $\beta$ expression, inhibited ASC speck formation and NLRP3 protein expression. In an acute gout mouse model, oral administration of TF to mice effectively alleviated paw edema, reduced inflammatory features, and decreased the levels of IL-1 $\beta$ in mouse foot tissue. Similarly, the characteristic constituent AM was also able to down-regulated the levels of NO, TNF$\alpha$, and LDH, down-regulate the mRNA expression of IL-1 $\beta$, TNF- $\alpha$, caspase-1, and NLRP3. Besides, the foot thickness, lymphocyte infiltration, and IL-1 $\beta$ level were also prevented by AM. 
Conclusion: The results indicated that TF and its main constituent AM alleviate gout arthritis via NLRP3/ASC/Caspase-1 axis suppression.

Keywords: Selaginella moellendorffii, biflavonoid, amentoflavone, NLRP3, gout

\section{INTRODUCTION}

Gout is the most common inflammatory arthritis characterized by chronic elevation of serum uric acid levels above a deposition threshold to form monosodium urate (MSU) crystal in joints or tissues (Kuo et al., 2015). The incidence of gout has been increasing in recent years due to changes in lifestyles. Generally, it occurs in men 2-6 folds higher than in women (Ragab et al., 2017). The acute attack of gout causes a severe inflammatory response, including redness, hotness, tenderness, and swelling (Ragab et al., 2017). If left untreated, it might ultimately progress to chronic arthritis, tophi depositions, as well as renal stones (Lu et al., 2019). The attack of gout seriously impairs the quality of life of patients.

The precipitation of MSU crystals in joints is considered a crucial factor in gout initiation and development (Shi et al., 2010). Some evidence has demonstrated that the MSU crystalinduced inflammatory responses and gout pathogenesis are dependent on NLRP3 inflammasome activation (Szekanecz et al., 2019; Punzi et al., 2020). The NLRP3 inflammasome, composed of receptor protein NLRP3, adaptor protein ASC, and effector protein pro-caspase-1, is a multiprotein complex of more than $700 \mathrm{kDa}$ (Petrilli et al., 2005). NLRP3 inflammasome can be activated by many different stimuli, including pathogen-associated molecular patterns (PAMPs) and danger-associated molecular patterns (DAMPs), such as MSU (Kingsbury et al., 2011; Guo et al., 2015). Once sensing specific activators, the sensor molecule NLRP3 undergoes conformational changes and then catalyzes ASC oligomerization to form the ASC "speck" (Vajjhala et al., 2012). As a macromolecular signaling platform, speck-like protein ASC then recruits the pro-caspase-1 via its C-terminal CARD domain, allowing for pro-caspase- 1 is cleaved to generate caspase-1(Srinivasula et al., 2002). Caspase-1 cleaves the pro-IL-1 $\beta$ and pro-IL-18 precursor into mature IL- $1 \beta$ and IL-18, leading to inflammation and tissue destruction (Fink and Cookson, 2006). The aberrant activation of the NLRP3 inflammasome is related to various diseases, including arthritis, cardiovascular disease, diabetes, and other rare genetic disorders (Dixit, 2013; Rowczenio et al., 2017; Yang et al., 2018; Zhou et al., 2018). Given the large number and diversity of NLRP3 inflammasome activators, searching for inhibitory agents targeting NLRP3 inflammasome might be a better choice for the treatment of NLRP3 inflammasome-related diseases.

Selaginella moellendorffii Hieron, a perennial herb of the Selaginella genus, is used as an ethnic drug to treat idiopathic thrombocytopenic purpura and hepatitis (Shi et al., 2008). S. moellendorffii are known to be rich in bioflavonoids (Cao et al., 2010), such as amentoflavone, robustaflavone, bilobetin, hinokiflavone, podocarpusflavone $\mathrm{A}$, and ginkgetin, which are responsible for the antiinflammatory and immunomodulatory effects (Lee et al., 1995; Lee et al., 1997). The potent ethnopharmacological properties of $S$. moellendorffii make it an excellent natural source of novel medicinal targets for NLRP3 inflammasomerelated gout treatment. In a previous study, the hospital preparation developed by our research group with the raw material of S. moellendorffii has achieved an excellent clinical effect on gout treatment. Its mechanism may be relevant to suppress NF- $\mathrm{KB}$ P65 activation and inflammatory mediator IL$1 \beta$ secretion (Zhang et al., 2019). These findings prompted us to investigate the possible mechanism of flavonoids in controlling NLRP3 inflammasome activation. In continuation with our previous work, the present study demonstrated the TF from $S$. moellendorffii exerted its antigout activity by inhibiting the NLRP3/ASC/Caspase-1 pathway.

\section{MATERIALS AND METHODS}

\section{Reagent}

AM (P09J8F37712) were obtained from Yuanye Bio-Technology (Shanghai, China), its purity was $\geq 99.0 \%$; LPS (L4391), MSU (U2875), and phorbol myristate acetate (PMA, P8139) were purchased from Sigma-Aldrich (St. Louis, United States). PI (E24567B117) and hoechst 33,342 (EZ5679A169) were purchased from BioFRoxx (Einhausen, DE). Colchicine (COL, C106740) was from Aladdin (Shanghai, China). TNF- $\alpha$ and IL-1 $\beta$ enzyme-linked immunosorbent assay (ELISA) kits were purchased from Jiancheng Bioengineering Institute (Nanjing, China). LDH and NO assay kits were purchased from Beyotime (Shanghai, China). Antibodies of $\beta$-actin, caspase- 1 , IL-1 $\beta$, NLRP3, and ASC were obtained from ABclonal (Wuhan, China). FITC-conjugated goat anti-rabbit IgG (GB22303) and HRP-conjugated goat anti-rabbit IgG were bought from Servicebio (Wuhan, China). All cell culture reagents were bought from Hyclone.

\section{Plant Material}

Intact plants of S. mollendorffii were purchased from Jointown Pharmaceutical Group Co., Ltd. (Wuhan, China), and specimens of these materials (S190712) were deposited in Hubei University of Chinese Medicine's herbarium. The plant material was authenticated by authors (Prof. Keli Chen).

\section{TF Preparation and Chemical Elucidation}

The dry plant material (5 $\mathrm{kg}$ ) was crushed and extracted with $85 \%$ ethanol for $1 \mathrm{~h}$ three times. The extract was filtered and then concentrated under the reduced pressure condition. The 
concentrated solution defatted with petroleum ether and then extracted with ethyl acetate. The ethyl acetate fraction $(60 \mathrm{~g})$ was successively dissolved with warm water and then subjected to D101 macroporous resin column chromatography eluted with $25,50,75,95 \%$ alcohol (V/V) in a gradient manner. The different fractions were collected and evaporated. Finally, according to the previous methods (Yin and Chen, 2010), the flavonoid contents of different fractions were detected by UV spectra. The 50\% ethanol fraction has total flavonoid content of $57.77 \pm 4.23 \%$ and showed the strongest anti-inflammation activity by decreasing NO secretion of RAW264.7 cells in response to LPS. This fraction was used as the purified flavonoid extract (TF, $6.3 \mathrm{~g}$ ) in this research.

The AM standard and TF were analyzed on Agilent 1260 Infinity II HPLC system and 6465B MS system. Separations were accomplished on an Agilent RRHD Eclipse Plus C18 $(2.1 \mathrm{~mm} \times$ $50 \mathrm{~mm}, 1.8 \mu \mathrm{m}$ ). The mobile phase consisted of acetonitrile (A) and water, including $0.1 \%$ formic acid (B). The degree program was $35-60 \% \mathrm{~A}$ in $1-15 \mathrm{~min}$. The flow rate was $0.2 \mathrm{ml} / \mathrm{min}$, and the column temperature was maintained at $30^{\circ} \mathrm{C}$. The injection volume was $2 \mu \mathrm{L}$. The detector was set at $330 \mathrm{~nm}$ for acquiring chromatograms.

The mass spectrometer was operated in positive ion mode with an AJS ESI source. The parameters were as follows: capillary voltage at $4000 \mathrm{~V}$, nozzle voltage at $1500 \mathrm{~V}$, fragmentor voltage at $100 \mathrm{~V}$. High-purity nitrogen was utilized as a sheath gas. The flow rate was set at $11 \mathrm{~L} / \mathrm{min}$ and gas temperature at $350^{\circ} \mathrm{C}$. The collision energy $(\mathrm{CE})$ was set at $45 \mathrm{~V}$. The $\mathrm{MS}^{2}$ scan was in the range of $50-500 \mathrm{~m} / z$, and the sweeping time was $500 \mathrm{~ms}$.

\section{Cell Culture and Treatments Cell Culture and Stimulation}

The mouse macrophage cell line RAW 264.7 and the human monocytic cell line THP-1 were provided by the China Center for Type Culture Collection of Wuhan University (Wuhan, China). RAW264.7 cells were cultured in Dulbecco's modified Eagle medium (DMEM) supplemented with $10 \%$ fetal bovine serum (FBS) and 1\% streptomycin/penicillin at $37^{\circ} \mathrm{C}$ with $5 \% \mathrm{CO}_{2}$. For treatment, the cells were pretreated with TF and AM for $2 \mathrm{~h}$ and subsequently treated by LPS $(0.5 \mu \mathrm{g} / \mathrm{ml})$ for $24 \mathrm{~h}$.

THP-1 cells were grown in RPMI 1640 medium supplemented with $10 \%$ FBS and $1 \%$ streptomycin/penicillin. Before experiments, THP-1 cells were differentiated in a medium containing $100 \mathrm{nM}$ PMA for $12 \mathrm{~h}$, and then rested in a fresh medium for 1 day. For inducing NLRP3 inflammasome activation, THP-1 macrophages were seeded in 24-well or 6well plates overnight, then the medium was changed to OptiMEM, cells were primed with LPS $(0.5 \mu \mathrm{g} / \mathrm{ml})$ for $3 \mathrm{~h}$, TF and AM were added for a further $1 \mathrm{~h}$, and finally, cells were stimulated with MSU $(150 \mu \mathrm{g} / \mathrm{ml})$ for $6 \mathrm{~h}$.

\section{Cell Viability Assay}

The cell counting kit-8 (CCK-8) assay was used to evaluate viability quantitatively. Briefly, the cells were seeded into
TABLE 1| The specific primers used in RT-PCR assay (Human).

\begin{tabular}{|c|c|c|}
\hline Gene name & Primer sequence $\left(5^{\prime}-3^{\prime}\right)$ & Length (bp) \\
\hline \multirow[t]{2}{*}{$I L-1 \beta$} & Forward: GAATCTCCGACCACCACTA & 190 \\
\hline & Reverse: ACATAAGCCTCGTTATCCC & \\
\hline \multirow[t]{2}{*}{ NLRP3 } & Forward: AACAGCCACСTCACTTCCAG & 169 \\
\hline & Reverse: CCAACCACAATCTCCGAATG & \\
\hline \multirow[t]{2}{*}{ Caspase-1 } & Forward: GCACAAGACCTCTGACAGCA & 146 \\
\hline & Reverse: TTGGGCAGTTCTTGGTATTC & \\
\hline \multirow[t]{2}{*}{ TNF- $\alpha$} & Forward: CTGGTATGAGCCCATCTATC & 296 \\
\hline & Reverse: CGAAGTGGTGGTCTTGTTGC & \\
\hline \multirow[t]{2}{*}{$\beta$-actin } & Forward: CCTGACTGACTACCTCATGAAG & 106 \\
\hline & Reverse: GACGTAGCACAGCTTCTCCTTA & \\
\hline
\end{tabular}

96-well plates. After incubation with a series of concentrations of test drugs diluted with culture medium for $24 \mathrm{~h}$, the medium was removed, $10 \%$ CCK- 8 reagent was added and incubated with cells for an additional $2 \mathrm{~h}$. Finally, a microplate reader (BioTek Instruments, Inc, United States) was used to measure the absorbance at a wavelength of $450 \mathrm{~nm}$.

\section{Inflammatory Cytokine Determination}

The cell supernatants were collected and stored at $-80^{\circ} \mathrm{C}$, then assayed for NO, IL-1 $\beta$, and TNF-a. According to the manufacturer's instructions, NO production was estimated according to the Griess method, whereas the quantification of IL- $1 \beta$ and TNF-a was performed using ELISA kits.

\section{LDH Release Assay}

After the THP-1 cells were treated mentioned above, the culture supernatants were harvested, and $\mathrm{LDH}$ levels were assessed by LDH cytotoxicity assay kit according to the manufacturer's instructions (Beyotime, Shanghai, China).

\section{SEM}

THP-1 cells were grown on round glass coverslips pre-coated with $1 \%$ poly-L-lysine. After treatment, the cell fixed with $2.5 \%$ glutaraldehyde overnight and then washed with PBS three times. The sample was dehydrated through ethanol series $(30,50,70,95$, and $100 \%)$, then dried by tertiary butanol method. Dried specimens were coated with gold-palladium and imaged with SEM operating at $30 \mathrm{kV}$ (JSM-6510LV; JEOL, Tokyo, Japan).

\section{RNA Preparation and RT-PCR}

Total RNA was extracted from THP-1 cells with Trizol kit (Tiangen, China), then the RNA was reverse transcribed into cDNA using the FastKing Kit (Tiangen, China). The relative levels of target gene mRNA to the control $\beta$-actin were determined by using SYBR Green PCR master mix and analyzed with a Light Cycler 480 (Roche, Germany). The primers were designed and composed by Sangon Biotech (shanghai) as follows (Table 1). RT-PCR was performed under the following conditions: one cycle of $95^{\circ} \mathrm{C}$ for $15 \mathrm{~min}$, and subjected to 40 cycles of $95^{\circ} \mathrm{C}$ for $10 \mathrm{~s}, 60^{\circ} \mathrm{C}$ for $40 \mathrm{~s}$ and $72^{\circ} \mathrm{C}$ for $32 \mathrm{~s}$. Duplicate assays were performed with all samples. The 


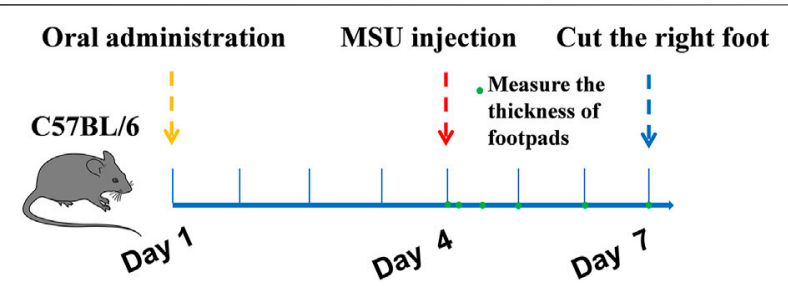

FIGURE 1 | Schematic experimental protocols.

expression of genes was calculated using the $\Delta \Delta \mathrm{Ct}$ method and expressed as fold change. RT-PCR products were resolved on $2.5 \%$ agarose gel and visualized with UV light after being stained with Green-DNA Dye.

\section{Hochest 33342 and PI Double Staining}

THP-1 cells $\left(2.5 \times 10^{6} /\right.$ well $)$ were cultured in a 6 -well plate and treated with test drugs mentioned above. Cells were stained with Hoechst $33342(10 \mu \mathrm{g} / \mathrm{ml}$, staining for all cells) for $20 \mathrm{~min}$ and propidium iodide (PI; $10 \mu \mathrm{g} / \mathrm{ml}$, staining for membrane-damaged cells) for $10 \mathrm{~min}$ in the dark at $37^{\circ} \mathrm{C}$. After that, the stained cells were observed under a fluorescence microscope (IX73; Olympus, Tokyo, Japan).

\section{Immunofluorescence}

Immunofluorescence was used to measure ASC speckles and NLRP3 protein expression. The cells were fixed with $4 \%$ buffered paraformaldehyde for $20 \mathrm{~min}$, then permeabilized with $0.2 \%$ Triton-X for $10 \mathrm{~min}$. After being washing several times, the cells were blocked with $6 \%$ goat serum in PBS for $1 \mathrm{~h}$, and incubated with the primary antibody (1:100 dilution) at $4^{\circ} \mathrm{C}$ overnight. Subsequently, the cells were incubated with FITC-conjugated anti-rabbit IgG (1:100 dilution) for $1 \mathrm{~h}$ in the dark at room temperature. DAPI was used for counterstaining the nuclei for $7 \mathrm{~min}$, and fluorescence was visualized using a fluorescence microscope at a magnification of $\times 200$. NLRP3 fluorescence intensity and ASC speckles were quantified using ImageJ software.

\section{Western Blot Assay}

THP-1 cells were lyzed on ice with RIPA lysis buffer. After quantifying protein concentration using a BCA kit, equal amounts of protein samples $(20 \mu \mathrm{g}$ per lane) were separated by
$12 \%$ SDS-PAGE and transferred onto PVDF membranes (Roche, Germany). The membranes incubated with primary antibodies $(1: 1000)$ diluted in $5 \%(\mathrm{w} / \mathrm{v})$ fat-free milk at $4^{\circ} \mathrm{C}$ overnight. After being washed and incubated with horseradish peroxidaseconjugated secondary antibodies, the protein bands were visualized using an enhanced chemiluminescence (ECL) Western blotting kit (Meilun, China) and densitometrically evaluated with ImageJ software. $\beta$-actin served as the internal standard.

\section{Animals and Treatments Animals}

Specific pathogen-free C57BL6 male mice weighing between 20 and $22 \mathrm{~g}$, were purchased from Changsheng biotechnology co, Ltd. (Liaoning, China). The Laboratory animal permission number was SCXK (Liao) 2020-0001. All mice were housed under standard laboratory conditions, including the air temperature $22 \pm 2^{\circ} \mathrm{C}$ and relative humidity $50 \pm 10 \%$ with a $12 \mathrm{~h}$ light-dark cycle. The experimental protocol in this study was approved by the Animal Ethical Committee of Hubei University of Chinese medicine (permission number: SYXK 2017-0067).

Induction of Gouty Arthritis With MSU Crystals in Mice The gout model was performed as previously described (Dhanasekar and Rasool, 2016; Lu et al., 2019). C57BL6 mice were divided into six groups $(n=10)$ : normal control group, MSU control group, colchicine group ( $2 \mathrm{mg} / \mathrm{kg} / \mathrm{d}), \mathrm{TF}$ group $(400,200,100 \mathrm{mg} / \mathrm{kg})$ and AM group (80, 40, $20 \mathrm{mg} / \mathrm{kg}$ ). Besides the normal control group, injected with $50 \mu \mathrm{L}$ sterile endotoxin-free saline, each group was subcutaneously injected with $50 \mu \mathrm{L}$ suspension of MSU $(50 \mathrm{mg} / \mathrm{ml})$ under the plantar surface of the right paw. Mice were orally fed with corresponding samples for one week. The control group and MSU group were also treated with $0.9 \%$ normal saline. Inflammatory paw edema was quantified by measuring the thickness of the paw with a Vernier scale at $0,4,12,24$, and $72 \mathrm{~h}$ after MSU crystal injections (Figure 1). The minimum accuracy of which is $0.01 \mathrm{~mm}$. Edema formation was described as the circumstance difference $(\Delta \mathrm{mm})$ between the basal value and the test value. At the end of the experimental period, all mice were anesthetized, and the foot samples were

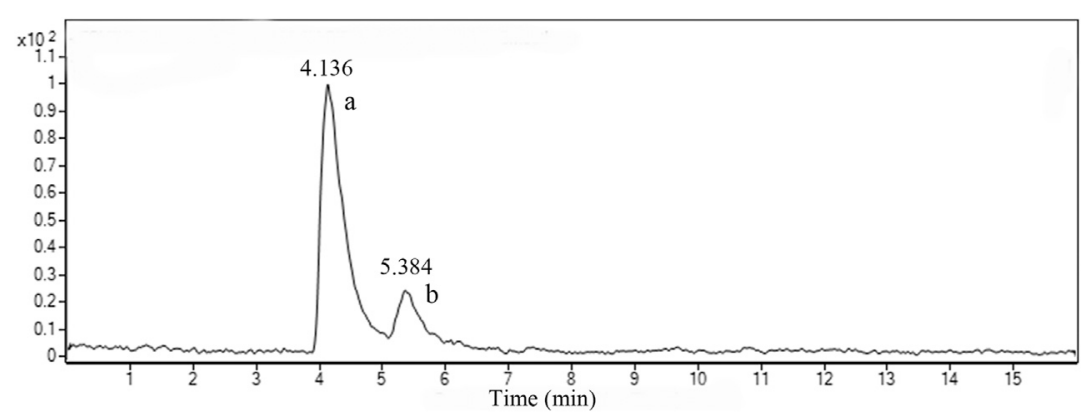

FIGURE 2 | TIC of TF in positive mode. a, amentoflavone; b, robustaflavone. 

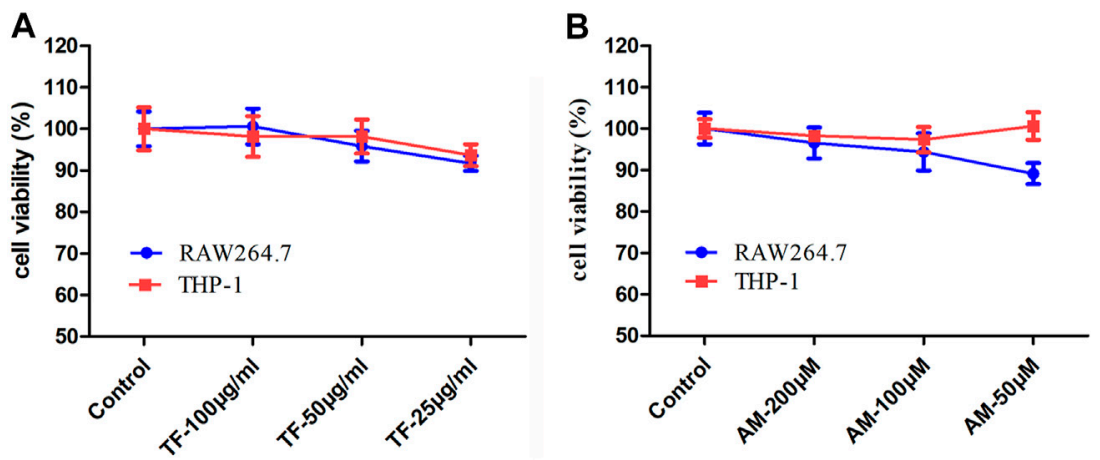

FIGURE 3|The effects of TF and AM on cytotoxicity in RAW264.7 cells and THP-1 cells. (A) Viability of RAW264.7 cells and THP-1 cells treated with TF. (B) Viability of RAW264.7 cells and THP-1 cells treated with AM. TF, flavonoid extract; AM, amentoflavone.

removed and stored at $-80^{\circ} \mathrm{C}$. The foot tissues were homogenized in $0.1 \mathrm{M}$ phosphate buffer ( $\mathrm{pH} 7.2$ ), and the supernatants were collected for IL-1 $\beta$ assays. For histological analysis, sagittal sections of the footpads were fixed in $4 \%$ paraformaldehyde, embedded in paraffin, and then stained with HE using standard techniques.
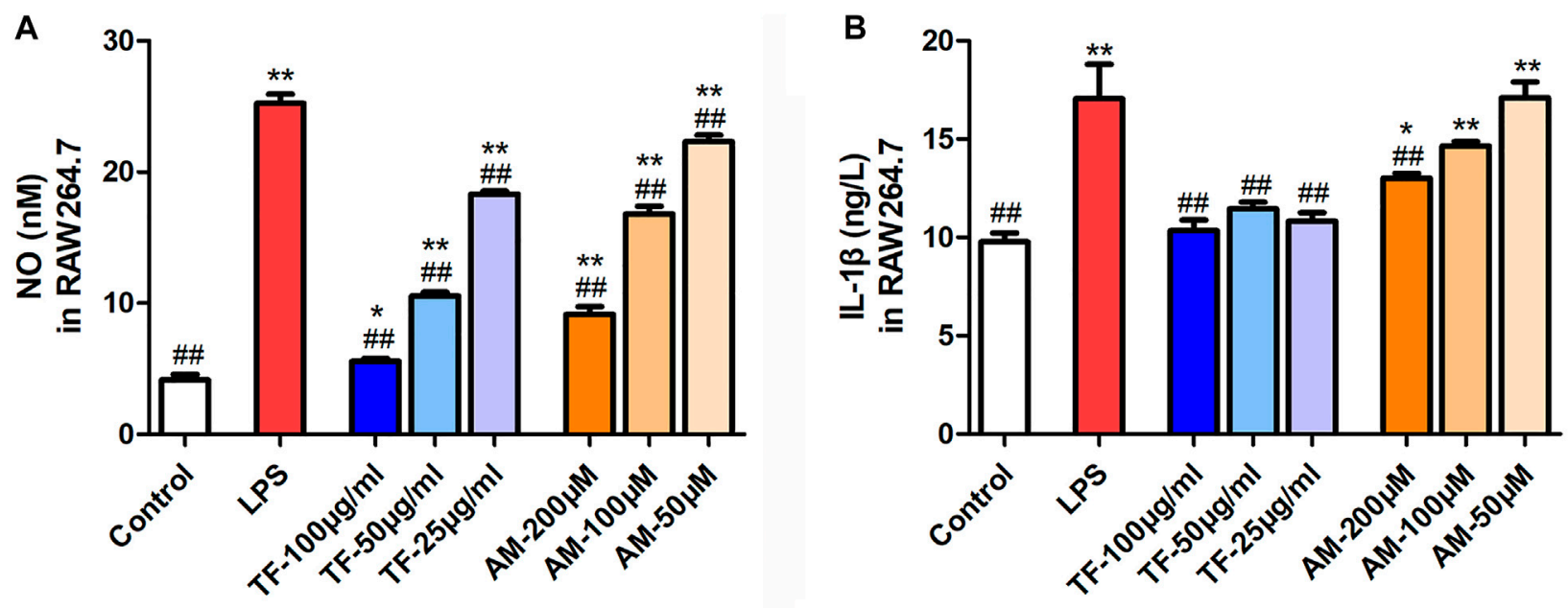

C
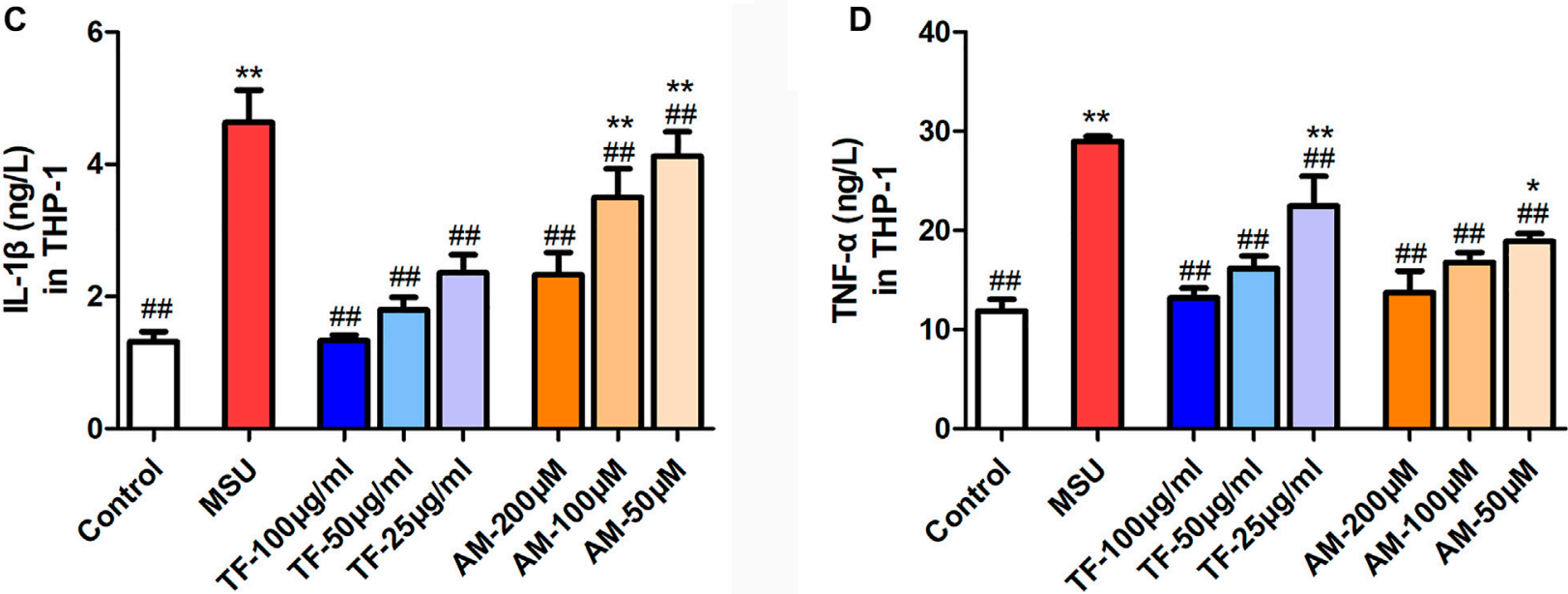

FIGURE 4 | The effects of TF and AM on inflammatory cytokine (A) The level of NO in the RAW264.7 cells (B) The level of IL-1 $\beta$ in the RAW264.7 cells (C) The level of $\mathrm{IL}-1 \beta$ in the THP-1 cells (D) The level of TNF- $\alpha$ in the THP-1 cells. ${ }^{*} p<0.05$ and ${ }^{* *} p<0.01$, significantly different the normal control group; ${ }^{\#} p<0.05$ and ${ }^{\# \#} p<0.01$, significantly different the LPS/MSU control group. TF, flavonoid extract; AM, amentoflavone. 

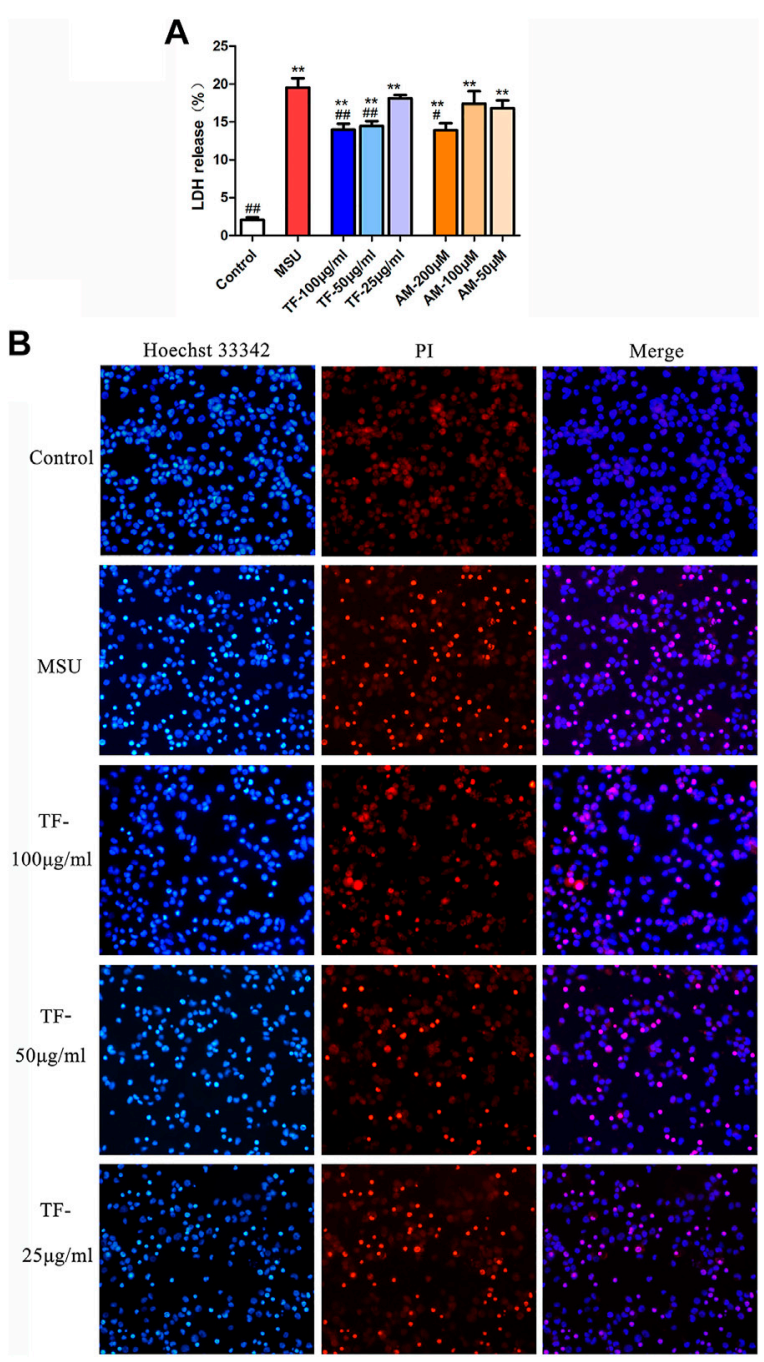

FIGURE 5 | Effects of TF and AM on membrane integrality in LPS/MSU-induced THP-1 cells (A) The rate of LDH release level. (B). Hochest33342 and PI double staining images were captured by fluorescence microscopy $(200 \times)$. Red shows membrane-damaged cells. Blue shows nuclei. ${ }^{*} p<0.05$ and ${ }^{\star \star} p<0.01$, significantly different the normal control group; ${ }^{\#} p<0.05$ and ${ }^{\# \#} p<0.01$, significantly different the LPS/MSU control group. TF, flavonoid extract; AM, amentoflavone.

\section{Statistical Analysis}

All measurement data were expressed as mean \pm standard error of the mean (SEM). Differences among multiple groups were assessed by one-way analysis of variance (ANOVA) and Newman-Keuls Multiple Comparison Test using the GraphPad Prism 5. $p<0.05$ was considered statistically significant.

\section{RESULTS}

\section{Chemical Characterization of TF}

Figure 2 shows the LC-MS total ion chromatograms (TIC) of $\mathrm{TF}$ in positive ESI-MS ${ }^{\mathrm{E}}$ mode. Two prominent peaks appeared in the chromatograms and their retention times (RT) were 4.136 and $5.384 \mathrm{~min}$, respectively. The quasi-molecular ion
$[\mathrm{M}+\mathrm{H}]+$ all at $m / z 539.1002$ in the positive ESI mode suggested the molecular formula $\mathrm{C}_{30} \mathrm{H}_{18} \mathrm{O}_{10}$. According to the standard compound peak, we initially speculated the peak a was AM. Based on the main fragmentations of mass spectrums in positive ESI-MS ${ }^{\mathrm{E}}$ mode and related literature (Wang et al., 2015), we deduced that peak b was most likely robustaflavone.

\section{Effects of TF and AM on Cytotoxicity in RAW264.7 Cells and THP-1 Cells}

As shown in Figure 3, the TF at a dose up to $100 \mu \mathrm{g} / \mathrm{ml}$ caused no cytotoxicity in RAW264.7 cells and THP-1 cells during $24 \mathrm{~h}$ treatment. Additionally, AM did not affect the cell viability in RAW264.7 cells and THP-1 cells up to $200 \mu \mathrm{M}$ $(p>0.05)$. 


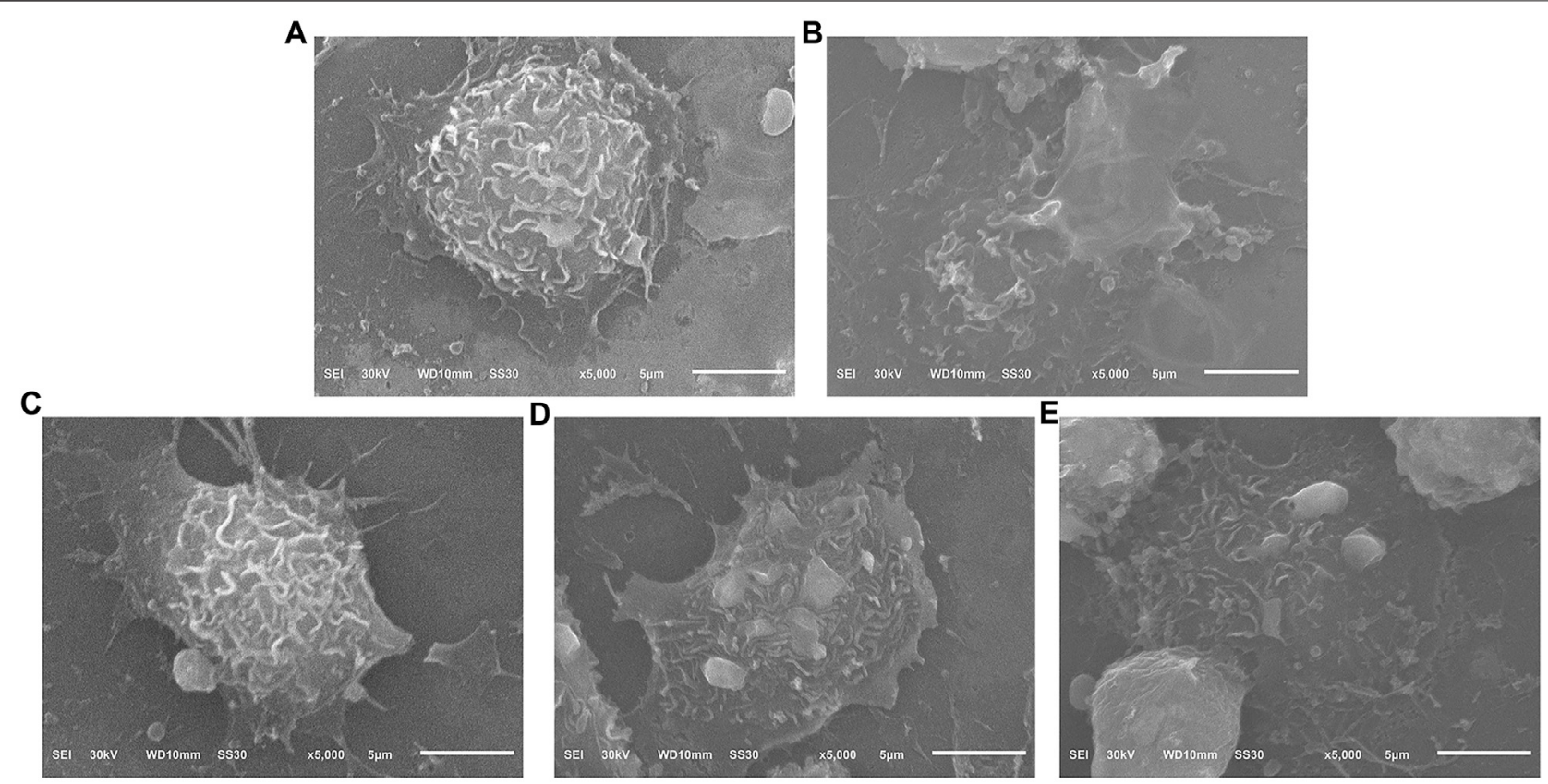

FIGURE 6 | Effects of TF on surface morphology in LPS/MSU-induced THP-1 macrophages ( $\times 5000)$. (A) Control group; (B) LPS/MSU group; (C) TF-100 $\mu \mathrm{g} / \mathrm{ml}$ group; (D) TF-50 $\mu \mathrm{g} / \mathrm{ml}$ group; (E) TF-25 $\mu \mathrm{g} / \mathrm{ml}$ group. Scale bar, $5 \mu \mathrm{m}$. TF, flavonoid extract.

\section{Effects of TF and AM on Inflammatory Cytokine in LPS-Induced RAW 264.7 Cells and LPS/MSU-Induced THP-1 Macrophages}

RAW 264.7 cells in the resting state released $4.13 \pm 0.87 \mathrm{nM}$ of NO during incubation for $24 \mathrm{~h}$, whereas the cells markedly increased NO production up to $25.23 \pm$ $1.44 \mathrm{nM}$ in response to LPS stimulation. When cells were pretreated with TF and AM, NO production was dosedependently inhibited (Figure 4A). As expected, TF and AM also decreased the level of IL-1 $\beta$ as compared with the LPS group $(p<0.05)$. In the meanwhile, IL-1 $\beta$ and TNF- $\alpha$ were determined in culture supernatant from the LPS/MSUinduced THP-1 cells. As shown in Figures 4C,D 25-100 $\mu \mathrm{g} / \mathrm{mL}$ TF and 50-200 $\mu \mathrm{M}$ AM could greatly down-regulate the levels of IL-1 $\beta$ and TNF- $\alpha(p<0.01)$.

\section{Effects of TF and AM on Membrane Integrality in LPS/MSU-Induced THP-1 Macrophages}

To further assess the influence of membrane integrality on LPS/ MSU-induced THP-1 cells pretreated with TF and AM, LDH release assay and Hochest 33342 and PI double staining were measured. As shown in Figure 5A, the LPS/MSU-induced LDH release significantly increased compared to the control group $(p<$ 0.01 ), while the increase in LDH level was prevented by both TF and $\mathrm{AM}(p<0.05, p<0.01)$. Besides, the percentage of membrane-damaged THP-1 macrophages (red) to the total cells (blue) upregulated after LPS/MSU stimulation, yet TF could partly downregulate the ratio of PI-positive cells in a dose-dependent manner (Figure 5B).

\section{Effects of TF on Surface Morphology in LPS/ MSU-Induced THP-1 Macrophages}

SEM analysis showed that THP-1 macrophages of the control group maintained a spherical morphology and a normal roughened surface, with only a few small extended lamellipodia (Figure 6A). By contrast, in LPS/MSU group, the cell membranes had lost their integrity. The cells showed mostly extended lamellipodia from the entire periphery of the cell and remained tightly attached to the culture slide, followed by cytoplasm flattening (Figure 6B). These characteristics were consistent with the late pyroptosis as previously reported (Chen et al., 2016b). After $100 \mu \mathrm{g} / \mathrm{mL}$ TF treatment, the cell contours became clearer, and surface villi became denser, indicating that pyroptosis characteristics were significantly reduced (Figures 6C-E).

\section{Effects of TF and AM on mRNA Expression in LPS/MSU-Induced THP-1 Macrophages}

To explore the underlying anti-inflammatory mechanisms, we investigated the inflammatory mediators including TNF- $\alpha$, IL-1 $\beta$, NLRP3, and caspase-1 in LPS/MSU-induced THP-1 macrophages. As shown in Figure 7, compared with the control group, the mRNA 
A
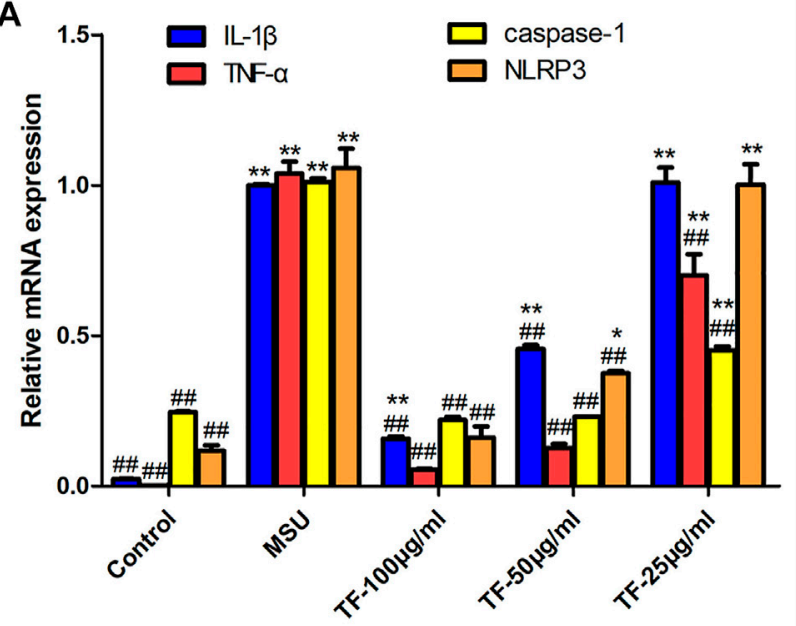

C

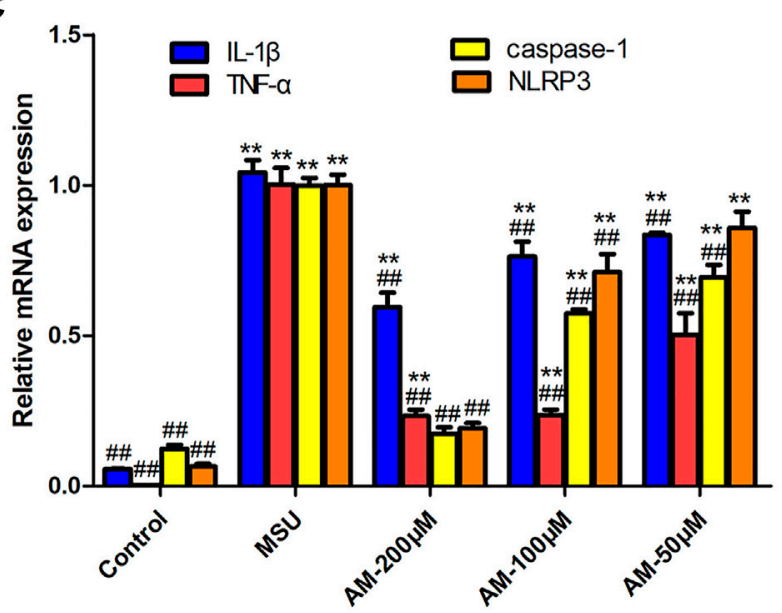

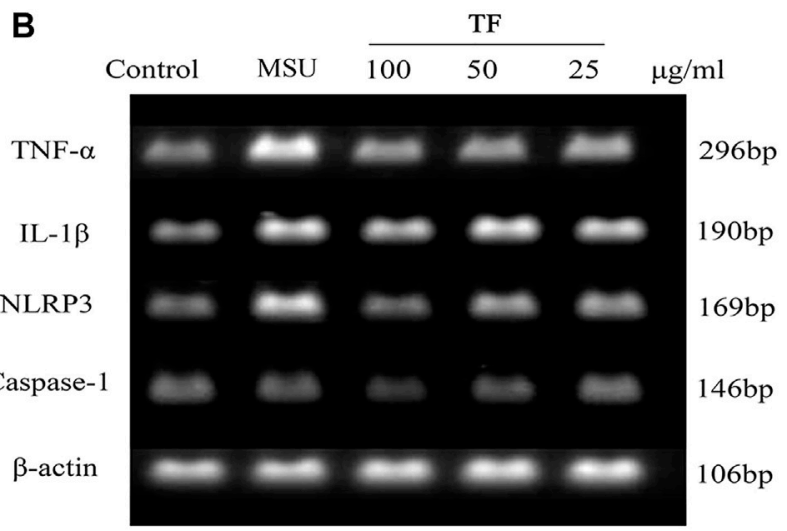

D
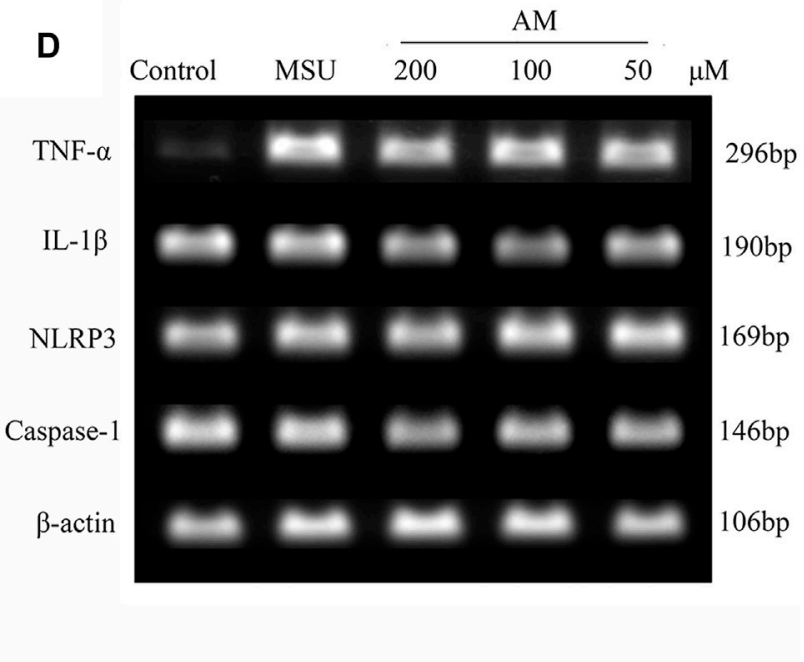

FIGURE 7| The Effects of TF and AM on mRNA in LPS/MSU-induced THP-1 macrophages. (A, C) The gene expressions of TNF- $\alpha$, IL-1 $\beta$, NLRP3 and caspase-1 mRNA (B, D) The detected bands of gene products. ${ }^{*} p<0.05$ and ${ }^{* *} p<0.01$, significantly different the normal control group; ${ }^{\#} p<0.05$ and ${ }^{\# \#} p<0.01$, significantly different the LPS/MSU control group. TF, flavonoid extract; AM, amentoflavone.

levels of TNF- $\alpha$, IL-1 $\beta$, NLRP3, and caspase-1 were significantly increased in the MSU group $(p<0.01)$. Conversely, pretreatment with $\mathrm{TF}$ and $\mathrm{AM}$ showed a significantly lower transcriptional level than those in the MSU group $(p<0.05)$.

\section{Effects of TF on ASC Speckle Formation and NLRP3 Expression in LPS/MSU-Induced THP-1 Macrophages}

ASC oligomerization is essential for NLRP3 inflammasome activation (Fernandes-Alnemri et al., 2007). As detected in THP-1 macrophages by immunofluorescent staining, ASC oligomerization to form large protein speckles at the perinuclear region was activated by LPS/MSU (Figure 8). Treatment of LPS/MSU-induced THP-1 macrophages with TF markedly reduced the formation of ASC speckles. Besides, the fluorescence intensity of NLRP3 protein was significantly enhanced by MSU (Figure 9). Indeed, pretreatment with
$100 \mu \mathrm{g} / \mathrm{mL}$ TF followed by MSU treatment significantly reduced the fluorescence intensity $(p<0.05)$. The immunofluorescence result was consistent with NLRP3 mRNA in terms of lowering NLRP3 expression.

\section{Effects of TF on IL-1 $\beta$ and Caspase-1 Expression in LPS/MSU-Induced THP-1 Macrophages}

Cleavage of the precursors proteins pro-caspase- 1 and pro-IL- $1 \beta$ to caspase-1 (p20) and IL-1 $\beta$ (p17), respectively, is considered another hallmark of NLRP3 inflammasome activation. By western blot, the amount of active caspase-1 p20 subunit was dose-dependently reduced in supernatants from $50 \mu \mathrm{g} / \mathrm{ml}$ and $100 \mu \mathrm{g} / \mathrm{mL}$ TF-treated macrophages (Figure 10), suggesting that TF inhibits the activation of caspase-1 by NLRP3. Correspondingly, the biologically active p17 form of IL- $1 \beta$ was inhibited by TF, consistent with the ELISA assay's data. 

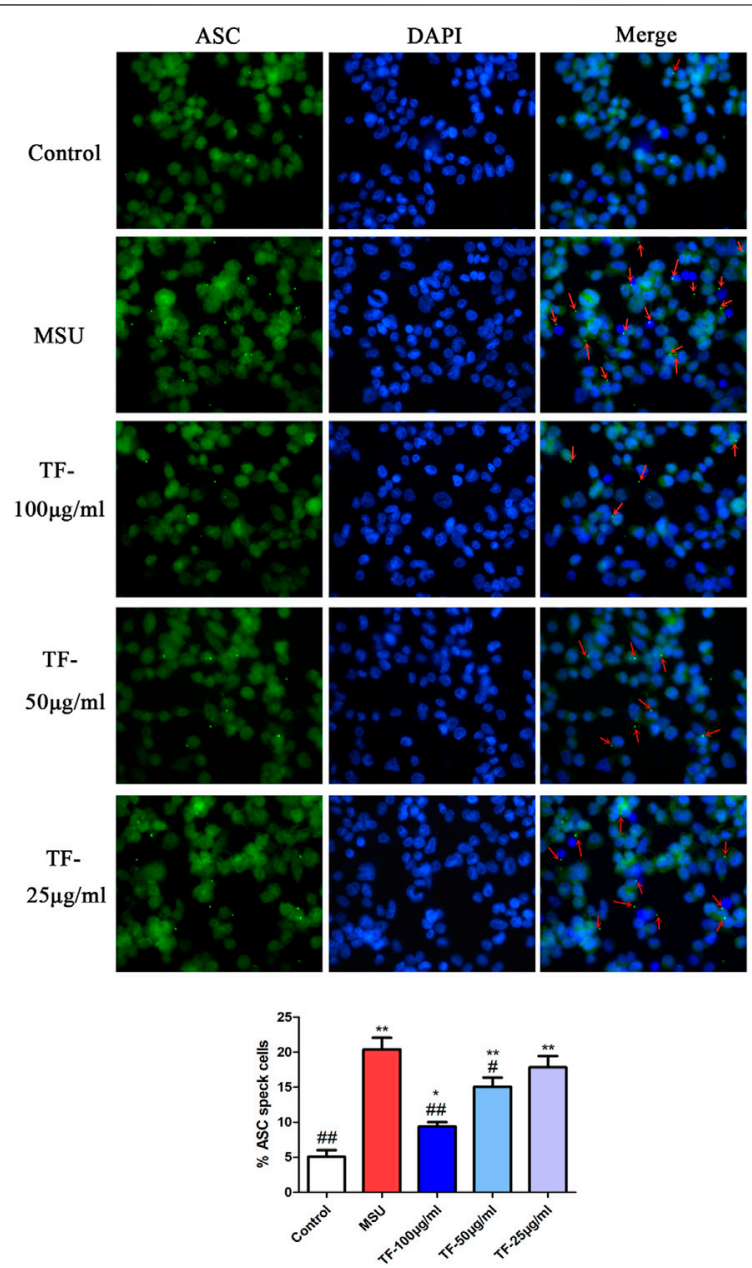

FIGURE 8 | Representative immunofluorescence images of ASC speckle. ASC (green) and DNA (blue). Arrow indicates ASC speckle. ${ }^{\star} p<0.05$ and ${ }^{\star \star} p<0.01$, significantly different the normal control group; ${ }^{\#} p<0.05$ and ${ }^{\# \#} p<0.01$, significantly different the LPS/MSU control group. TF, flavonoid extract.

Moreover, TF treatment consistently decreased the expression of pro-IL-1 $\beta$ or pro-caspase-1 in cell lysates as well.

\section{Effects of TF and AM on Gout in MSU-Induced Mice}

We measured the paws' thickness after MSU crystal injections. Consistent with the observed increase in paw swelling (Figure 11C), the MSU-induced mice led to a significant increase in foot thickness compared to the control group. This effect reached the peak at $24 \mathrm{~h}$, and the foot thickness increased $0.90 \pm 0.19 \mathrm{~mm}$ after injection (Figure 11 A,B). However, TF and AM administration ameliorated MSU-induced paw edema in a dose-dependent manner to a certain extent $(p<0.05, p<0.01)$. Especially, TF $(400 \mathrm{mg} / \mathrm{kg})$ exhibited significantly inhibited MSUinduced paw edema at all evaluated time points, similar to that of colchicine $(2 \mathrm{mg} / \mathrm{kg}, p>0.05)$. Meanwhile, the IL- $1 \beta$ level of the TF and AM group was also effectively reduced compared to the MSU group $(p<0.05)$, and the effect of $400 \mathrm{mg} / \mathrm{kg}$ TF and $80 \mathrm{mg} / \mathrm{kg} \mathrm{AM}$ were comparable to the colchicine treated group (Figure 12). Histological assessment of the control group revealed the footpad's typical architecture with regular cell arrangements and the absence of abnormal inflammatory cells in the skeletal muscle tissue, fibrotendinous tissue, and subcutaneous tissue (Figure 13A). In the model group, inflammatory cell infiltrations, erosion, and congestion in the subcutaneous soft tissue could be seen from the footpad tissue section (Figure 13B). In contrast, TF and AM with the high dosage treatment could visibly suppress the influx of inflammatory cells, similarly to the colchicine group (Figures 13C-E).

\section{DISCUSSION}

Recently, the development of anti-gout drugs from natural products has attracted worldwide attention for its greater safety and effectiveness. Flavonoids, a class of low or no toxic compounds contrasting to non-steroidal anti-inflammatory 

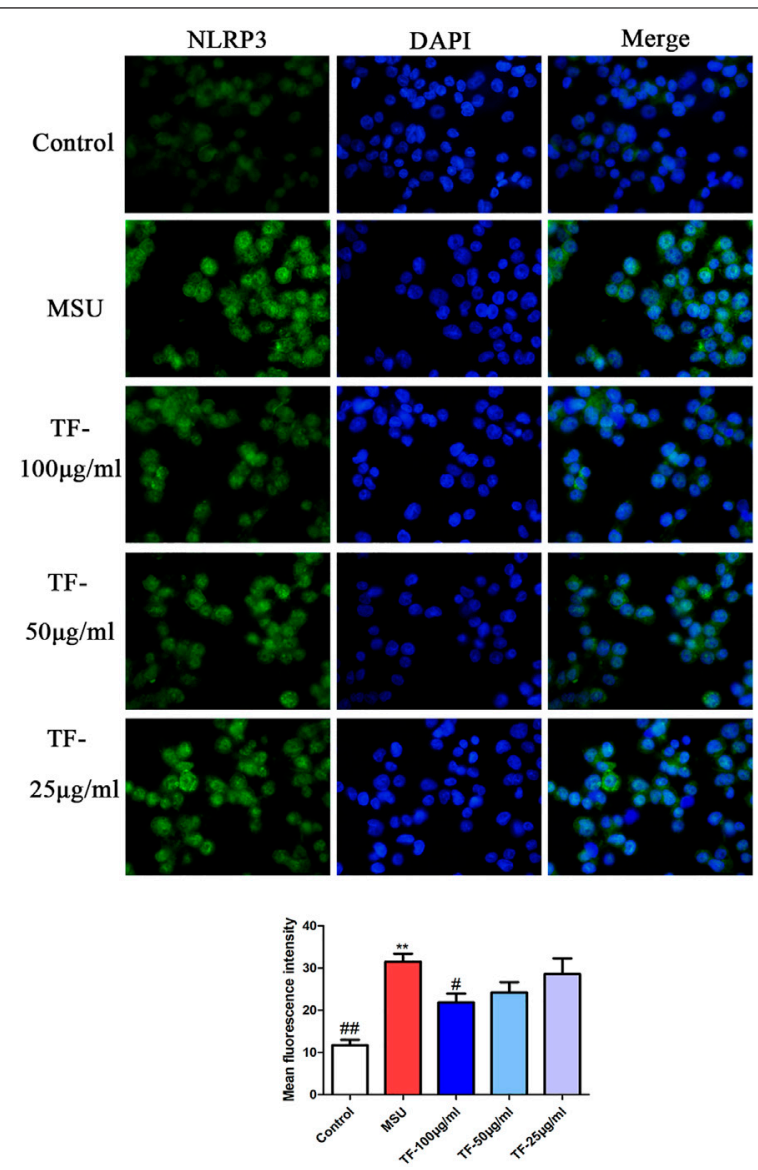

FIGURE 9 | Representative immunofluorescence images of NLRP3 protein. NLRP3 (green) and DNA (blue). ${ }^{*} p<0.05$ and ${ }^{* *} p<0.01$, significantly different the normal control group; $\# p<0.05$ and \#\#p < 0.01, significantly different the LPS/MSU control group. TF, flavonoid extract.

drugs, are ideal candidates for gouty arthritis with antiinflammatory and XOD inhibitory activity. Chemical constituents previously reported of S. moellendorffii included flavonoids, alkaloids, and phenylpropanoids. In our previous research, AM, 4"-O-methylrobustaflavone, 6,8-di-C$\beta$-D-glucopyranosyl apigenin, 6-C- $\beta$-D-glucopyranosyl-8-C$\beta$-D-xylopyranosyl apigenin, and 6-C- $\beta$-D-xylopyranosyl-8-C$\beta$-D-glucopyranosyl apigenin were isolated from this plant (Zhu et al., 2008). We then investigated these flavonoids' antiinflammation activities by examining NO secretion of RAW264.7 cells in response to LPS. We found that flavonoid aglycones played a more significant anti-inflammatory activity in vitro (data not shown here). In this study, TF purified from ethyl acetate extract was rich in flavonoid aglycones, and AM was its main component. Further research revealed that TF and AM both exhibited remarkable anti-inflammation activity by suppressing NO, IL- $1 \beta$, and TNF- $\alpha$ production in the cell inflammation model. Previous reports have shown that AM had antiinflammation, anti-oxidation, anti-tumor, and anti-virus functions (Yu et al., 2017), and inhibiting IL-1 $\beta$ and ICAM-1 by AM may lead to gout suppression in MSU-induced HUVECs (Chen et al., 2016a). Our results further demonstrate that AM is effective in preventing acute gout. Additionally, Jo et al. (2019) reported that robustaflavone could strongly reduce the production of NO, IL- $1 \beta$, and IL- 6 at the concentration of $10 \mu \mathrm{M}$. Therefore, we deduced AM and robustaflavone might be responsible for the anti-inflammatory effect of TF.

Activation of NLRP3 inflammasome is the core event of gout. NLRP3 inflammasome activation involves two steps. The first signal, also known as the priming signal, activates the NF- $\kappa B$ pathway, inducing the expression of pro-IL- $1 \beta$ and NLRP3 mRNA. The second step, activation signal, is transduced by various PAMPs and DAMPs, resulting in the formation of the inflammasome complex and the subsequent activation of caspase-1 (Place and Kanneganti, 2018). Here, pretreatment with TF and AM significantly inhibited the IL- $1 \beta$ secretion and caspase- 1 cleavage in a dose-dependent manner. These results suggested that TF inhibited NLRP3 inflammasome activation. ASC on mitochondria bridges NLRP3 and caspase-1 to form NLRP3 ternary inflammasome complexes (Compan et al., 2015). However, treatment with TF markedly reduced ASC speckles' formation, suggesting TF may block the assembly of NLRP3 inflammasome characterized by less formation of 
A

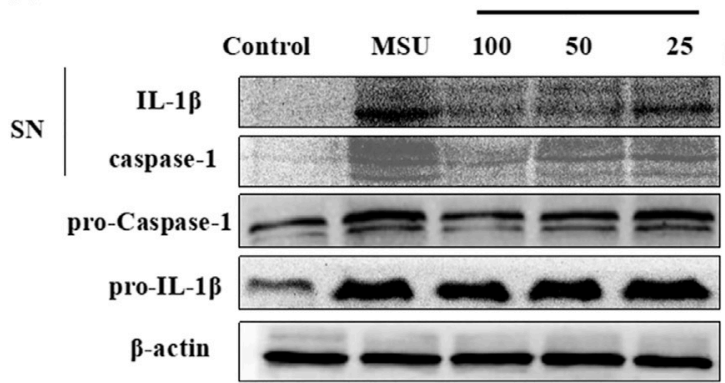

B

Ig/ml

$17 \mathrm{kDa}$

20KDa

45KDa

31 KDa

43KDa

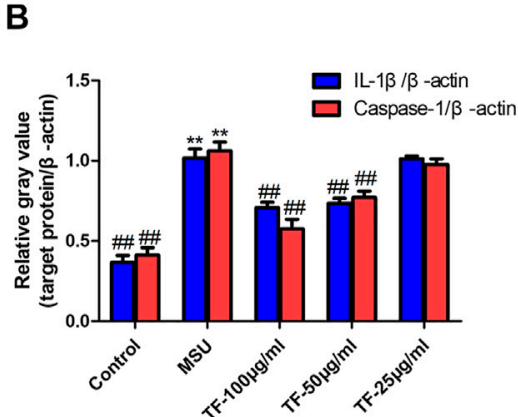

FIGURE 10 | Effects of TF on IL-1 $\beta$ and caspase-1 expression in LPS/MSU-induced THP- 1 macrophages. (A) Immunoblot analysis of IL-1 $\beta$ and active caspase-1 in supernatants and cell lysates of THP-1 macrophages treated with TF. (B) Relative gray value of target protein over $\beta$-actin. ${ }^{*} p<0.05$ and ${ }^{* *} p<0.01$, significantly different the normal control group; ${ }^{\#} p<0.05$ and ${ }^{\# \#} p<0.01$, significantly different the LPS/MSU control group. SN, medium supernatants; TF, flavonoid extract.
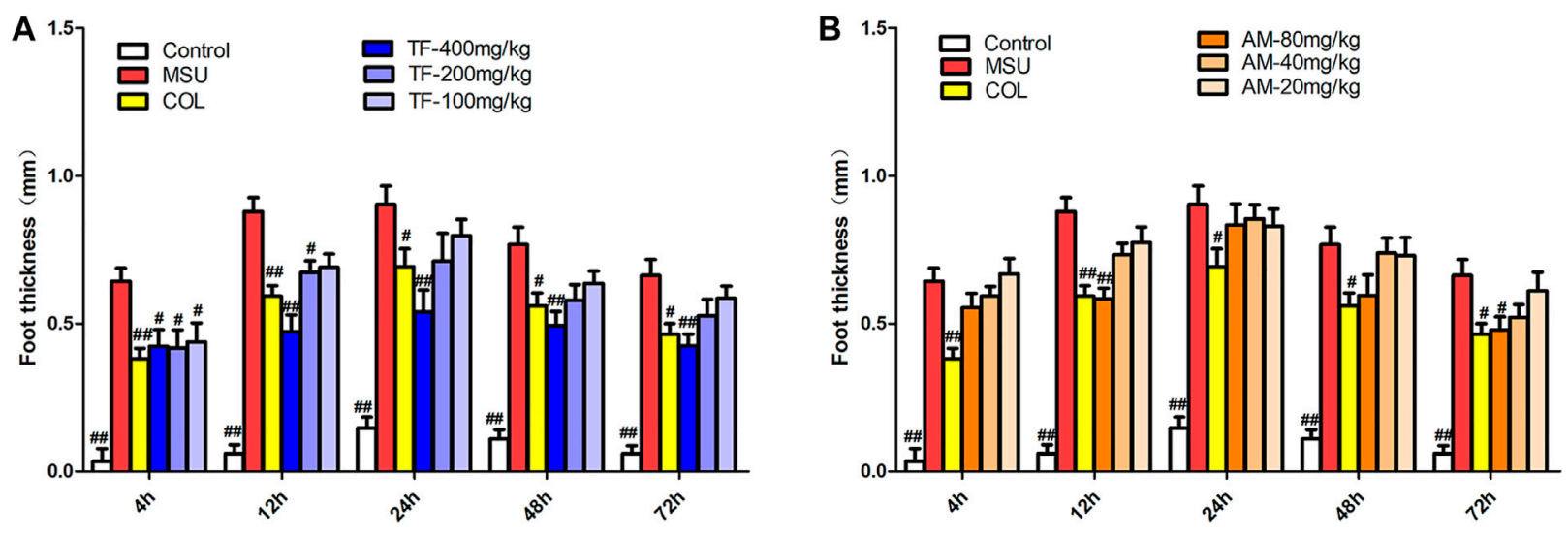

C
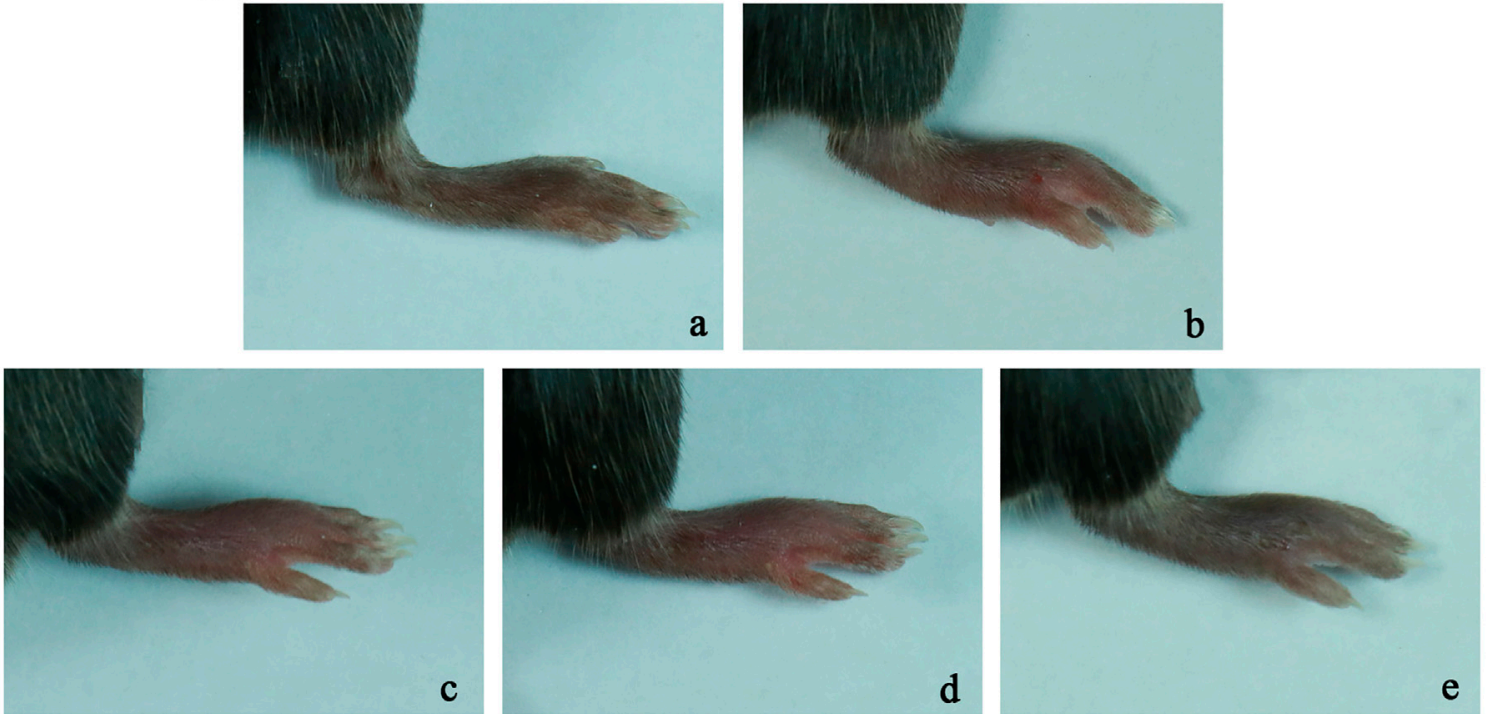

FIGURE 11 | Effects of TF and AM on paw swelling in MSU-induced mice. (A, B) Time course of footpad thickness gain compared with the footpad thickness at the 0 h time point per group; (C) Paw joint inflammation severity was observed macroscopically. a, Normal control group; b, MSU control group; c, colchicine group; d, TF$400 \mathrm{mg} / \mathrm{kg}$ group; e, AM-80 mg/kg group. ${ }^{*} p<0.05$ and ${ }^{* *} p<0.01$, significantly different the normal control group; ${ }^{\#} p<0.05$ and ${ }^{\# \#} p<0.01$, significantly different the LPS/MSU control group. TF, flavonoid extract; AM, amentoflavone. 


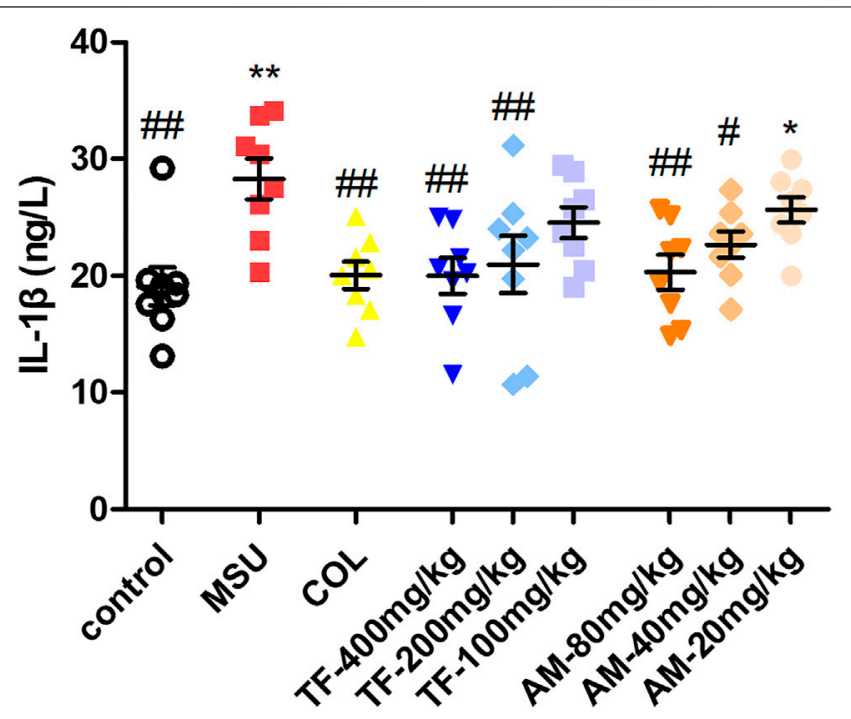

FIGURE 12| Effects of TF and AM on IL-1 $\beta$ level in MSU-induced mice. Supernatants of the foot tissue homogenates were analyzed for IL-1 $\beta$ after TF treatmentand AM treatment. ${ }^{*} p<0.05$ and ${ }^{* *} p<0.01$, significantly different the normal control group; ${ }^{*} p<0.05$ and ${ }^{\# \#} p<0.01$, significantly different the LPS/MSU control group. TF, flavonoid extract; AM, amentoflavone.

13 Representative picture of HE staining of the right footpad at plantar side (200x). Infiltrated neutrophils in the hind foot tissue appear as purple dots in HE staining. (A) , Normal control group; (B) , MSU control group; (C) , colchicine group; (D), TF-400 mg/kg group; (E), AM-80 mg/kg group. TF flavonoid extract; AM, amentoflavone.

ASC speckles and expression of NLRP3. Activation of caspase-1 not only leads to inflammation but in certain instances causes an inflammatory form of cell death called pyroptosis (Fink and Cookson, 2006). It is characterized by cell swelling, lysis, and release of pro-inflammatory cytokines and intracellular contents such as LDH (Fink and Cookson, 2006). However, we further found that TF could significantly reduction $\mathrm{LDH}$ release and the percentage of PI-positive cells. By SEM, THP-1 cells that were exposed to $100 \mu \mathrm{g} / \mathrm{mL}$ TF exhibited pronounced cell rounding with a few small extended lamellipodia. The data suggested that TF pretreatment inhibited MSU-induced cell inflammation by improving cell membrane integrity and protecting cell morphology. Therefore, the results indicated that TF alleviated LPS/MSU induced cellular gout model via regulation of NLRP3/ASC/Caspase-1 signaling pathway.

Intradermal injection of MSU crystals into the footpad has been regarded as a classical model to reproduce gouty arthritis experimentally. After taking in the MSU crystals, the secretion of IL- $1 \beta$ and TNF- $\alpha$ via monocytes is promoted. IL- $1 \beta$ has emerged as an important indicator to assess the acute gout model (So et al., 2018). The accumulation of IL-1 $\beta$ causes 
synovial lesions, cartilage destruction, and neutrophil infiltration. Interestingly, TF and AM could markedly relieve paw swelling and decrease IL-1 $\beta$ levels. As further positive evidence, administration of TF and AM successfully alleviated the pathologic changes of the footpad in mice injected with MSU as detected by HE staining. These successfully confirmed that TF and AM had good effects on acute gouty arthritis by reducing foot thickness, IL- $1 \beta$ level, and lymphocyte infiltration.

Collectively, TF may influence the NLRP3 inflammasome activation by inhibiting mRNA levels of IL- $1 \beta$, TNF- $\alpha$, NLRP3, and caspase-1, reducing the formation of ASC speckles and decreasing the expression of NLRP3, whereas inhibiting downstream signal molecular IL-1 $\beta$ release and caspase-1-dependent cell pyroptosis. Our results further confirmed that TF and its main constituent AM could prevent MSU-induced gout in vivo. Thus, TF may have preventive or therapeutic potential against acute gout via regulation of NLRP3/ ASC/Caspase-1 signaling pathway.

\section{DATA AVAILABILITY STATEMENT}

The original contributions presented in the study are included in the article/Supplementary Material, further inquiries can be directed to the corresponding author.

\section{REFERENCES}

Cao, Y., Tan, N.-H., Chen, J.-J., Zeng, G.-Z., Ma, Y.-B., Wu, Y.-P., et al. (2010). Bioactive Flavones and Biflavones from Selaginella Moellendorffii Hieron. Fitoterapia 81 (4), 253-258. doi:10.1016/j.fitote.2009.09.007

Chen, W. J., Wu, Y., Zhao, X., Liu, S., Song, F. R., Liu, Z. Y., et al. (2016a). Screening the Anti-Gout Traditional Herbs From TCM Using an in Vitro Method. Chin. Chem. Lett. 27, 1701-1707. doi:10.1016/j.cclet.2016.05.022

Chen, X., He, W.-t., Hu, L., Li, J., Fang, Y., Wang, X., et al. (2016b). Pyroptosis Is Driven by Non-selective Gasdermin-D Pore and its Morphology Is Different from MLKL Channel-Mediated Necroptosis. Cell Res. 26 (9), 1007-1020. doi:10.1038/cr.2016.100

Compan, V., Martin-Sanchez, F., Baroja-Mazo, A., Lopez-Castejon, G., Gomez, A. I., Verkhratsky, A., et al. (2015). Apoptosis-Associated Speck-Like Protein Containing a CARD Forms Specks but does not Activate Caspase-1 in the Absence of NLRP3 During Macrophage Swelling. J. Immunol. 194, 1261-1273. doi:10.4049/jimmunol.1301676

Dhanasekar, C., and Rasool, M. (2016). Morin, a Dietary Bioflavonol Suppresses Monosodium Urate Crystal-Induced Inflammation in an Animal Model of Acute Gouty Arthritis with Reference to NLRP3 Inflammasome, HypoXanthine Phospho-Ribosyl Transferase, and Inflammatory Mediators. Eur. J. Pharmacol. 786, 116-127. doi:10.1016/j.ejphar.2016.06.005

Dixit, V. D. (2013). Nlrp3 Inflammasome Activation in Type 2 Diabetes: Is it Clinically Relevant? Diabetes 62 (1), 22-24. doi:10.2337/db12-1115

Fernandes-Alnemri, T., Wu, J., Yu, J.-W., Datta, P., Miller, B., Jankowski, W., et al. (2007). The Pyroptosome: a Supramolecular Assembly of ASC Dimers Mediating Inflammatory Cell Death via Caspase-1 Activation. Cell Death Differ. 14 (9), 1590-1604. doi:10.1038/sj.cdd.4402194

Fink, S. L., and Cookson, B. T. (2006). Caspase-1-dependent Pore Formation during Pyroptosis Leads to Osmotic Lysis of Infected Host Macrophages. Cell. Microbiol. 8 (11), 1812-1825. doi:10.1111/j.1462-5822.2006.00751.x

Guo, H., Callaway, J. B., and Ting, J. P.-Y. (2015). Inflammasomes: Mechanism of Action, Role in Disease, and Therapeutics. Nat. Med. 21 (7), 677-687. doi:10. 1038/nm.3893

\section{ETHICS STATEMENT}

The animal study was reviewed and approved by the Center Laboratory of Chinese Medicine, Hubei University of Chinese Medicine.

\section{AUTHOR CONTRIBUTIONS}

JL, GD, and KC conceived and designed the experiment. XZ and YL performed the experiment. $\mathrm{XZ}$ and $\mathrm{BH}$ carried out literature search and manuscript editing. GK and JL analyzed the data and wrote the manuscript. All authors have read and approved the final article.

\section{FUNDING}

This work was funded by the National Natural Science Foundation of China (81903921); the Key project at central government level: The ability establishment of sustainable use for valuable Chinese medicine resources (2060302); the Opening Project of Zhejiang Provincial Preponderant and Characteristic Subject of Key University (Traditional Chinese Pharmacology), Zhejiang Chinese Medical University (No. ZYAOXYB2019003) Hubei Provincial Key Laboratory of Occurrence and Intervention of Rheumatic Diseases, Hubei Minzu University (PT022002).

Jo, A., Yoo, H. J., and Lee, M. (2019). Robustaflavone Isolated from Nandina domestica Using Bioactivity-Guided Fractionation Downregulates Inflammatory Mediators. Molecules 24. doi:10.3390/molecules24091789

Kingsbury, S. R., Conaghan, P. G., and McDermott, M. F. (2011). The Role of the NLRP3 Inflammasome in Gout. J. Inflamm. Res. 4, 39-49. doi:10.2147/JIR. S11330

Kuo, C.-F., Grainge, M. J., Zhang, W., and Doherty, M. (2015). Global Epidemiology of Gout: Prevalence, Incidence and Risk Factors. Nat. Rev. Rheumatol. 11 (11), 649-662. doi:10.1038/nrrheum.2015.91

Lee, S. J., Choi, J. H., Son, K. H., Chang, H. W., kang, S. S., and Kim, H. P. (1995). Suppression of Mouse Lymphocyte Proliferation In Vitro by NaturallyOccurring Biflavonoids. Life Sci. 57 (6), 551-558. doi:10.1016/0024-3205(95) 00305-p

Lee, S. J., Son, K. H., Chang, H. W., Kang, S. S., and Kim, H. P. (1997). Inhibition of Arachidonate Release from Rat Peritoneal Macrophage by Biflavonoids. Arch. Pharm. Res. 20 (6), 533-538. doi:10.1007/BF02975207

Lu, X., Zeng, R., Lin, J., Hu, J., Rong, Z., Xu, W., et al. (2019). Pharmacological Basis for Use of Madecassoside in Gouty Arthritis: Anti-inflammatory, Antihyperuricemic, and NLRP3 Inhibition. Immunopharmacol. Immunotoxicol. 41 (2), 277-284. doi:10.1080/08923973.2019.1590721

Petrilli, V., Papin, S., and Tschopp, J. (2005). The Inflammasome. Curr. Biol. 15 (15), R581. doi:10.1016/j.cub.2005.07.049

Punzi, L., Scanu, A., Galozzi, P., Luisetto, R., Spinella, P., Scirè, C. A., et al. (2020). One Year in Review 2020: goutGout: An Old Disease in New Perspective - A Review. Clin. Exp. Rheumatol.J Adv. Res. 388 (5), 807495-821511. doi:10.1016/j. jare.2017.04.008

Ragab, G., Elshahaly, M., and Bardin, T. (2017). Gout: An old Disease in new Perspective-A Review. J. Adv. Res. 8, 495-511. doi:10.1016/j.jare.2017. 04.008

Rowczenio, D. M., Gomes, S. M., Aróstegui, J. I., Mensa-Vilaro, A., Omoyinmi, E., Trojer, H., et al. (2017). Late-Onset Cryopyrin-Associated Periodic Syndromes Caused by Somatic NLRP3 Mosaicism-UK Single Center Experience. Front. Immunol. 8, 1410. doi:10.3389/fimmu.2017.01410

Shi, S., Zhou, H., Zhang, Y., and Huang, K. (2008). Hyphenated HSCCCDPPH. for Rapid Preparative Isolation and Screening of Antioxidants 
from Selaginella Moellendorffii. Chroma. 68, 173-178. doi:10.1365/ s10337-008-0716-1

Shi, Y., Mucsi, A. D., Ng, G., Srinivasula, S. M., Poyet, J. L., Razmara, M., et al. (2010). Monosodium Urate Crystals in Inflammation and immunityThe PYRIN-CARD Protein ASC Is an Activating Adaptor for Caspase-1. Immunol. Rev.J. Biol. Chem. 233233 (1), 203203-217217. doi:10.1111/j.01052896.2009.00851.x

So, A., Dumusc, A., and Nasi, S. (2018). The role of IL-1 in gout: from bench to bedside. Rheumatology (Oxford) 57, i12-i19. doi:10.4049/jimmunol.1301676

Srinivasula, S. M., Poyet, J. L., Razmara, M., Datta, P., Zhang, Z., and Alnemri, E. S. (2002). The PYRIN-CARD Protein ASC is an Activating Adaptor for Caspase-1. J. Biol. Chem. 277, 21119-21122. doi:10.1074/jbc.C200179200

Szekanecz, Z., Szamosi, S., Kovács, G. E., Kocsis, E., and Benkő, S. (2019). The NLRP3 Inflammasome - Interleukin 1 Pathway as a Therapeutic Target in Gout. Arch. Biochem. Biophys. 670, 82-93. doi:10.1016/j.abb. 2019.01.031

Vajjhala, P. R., Mirams, R. E., and Hill, J. M. (2012). Multiple Binding Sites on the Pyrin Domain of ASC Protein Allow Self-Association and Interaction with NLRP3 Protein*. J. Biol. Chem. 287 (50), 41732-41743. doi:10.1074/jbc.M112. 381228

Wang, G., Yao, S., Zhang, X.-X., and Song, H. (2015). Rapid Screening and Structural Characterization of Antioxidants from the Extract ofSelaginella doederleiniiHieron with DPPH-UPLC-Q-TOF/MS Method. Int. J. Anal. Chem. 2015, 849769. doi:10.1155/2015/849769

Yang, G., Yeon, S. H., Lee, H. E., Kang, H. C., Cho, Y. Y., Lee, H. S., et al. (2018). Suppression of NLRP3 Inflammasome by Oral Treatment with Sulforaphane Alleviates Acute Gouty Inflammation. Rheumatology 57 (4), 727-736. doi:10. 1093/rheumatology/kex499
Yin, D., and Chen, K. L. (2010). Purification Technology of Total Flavonoids from Selaginella Moellendorfii Hieron with Macroporous Adsorption Resin. Chin. J. Pharm. Anal. 30 (11), 2040-2043. doi:10.16155/j.0254

Yu, S., Yan, H., Zhang, L., Shan, M., Chen, P., Ding, A., et al. (2017). A Review on the Phytochemistry, Pharmacology, and Pharmacokinetics of Amentoflavone, a Naturally-Occurring Biflavonoid. Molecules 22. doi:10.3390/molecules22020299

Zhang, X.-y., Cheng, J., Zhao, P., Chen, K.-I., and Li, J. (2019). Screening the Best Compatibility of Selaginella Moellendorffii Prescription on Hyperuricemia and Gouty Arthritis and its Mechanism. Evidence-Based Complement. Altern. Med. 2019, 7263034. doi:10.1155/2019/7263034

Zhou, W., Chen, C., Chen, Z., Liu, L., Jiang, J., Wu, Z., et al. (2018). NLRP3: A Novel Mediator in Cardiovascular Disease. J. Immunol. Res. 2018, 5702103. doi:10.1155/2018/5702103

Zhu, T. M., Chen, K. L., and Zhou, W. B. (2008). A new Flavone Glycoside From Selaginella Moellendorffii Hieron. Chin. Chem. Lett. 19, 1456-1458. doi:10. 1016/j.cclet.2008.09.042

Conflict of Interest: The authors declare that the research was conducted in the absence of any commercial or financial relationships that could be construed as a potential conflict of interest.

Copyright $\odot 2021$ Zhang, Liu, Deng, Huang, Kai, chen and Li. This is an open-access article distributed under the terms of the Creative Commons Attribution License (CC $B Y$ ). The use, distribution or reproduction in other forums is permitted, provided the original author(s) and the copyright owner(s) are credited and that the original publication in this journal is cited, in accordance with accepted academic practice. No use, distribution or reproduction is permitted which does not comply with these terms. 